\title{
As Torcidas Organizadas do "Trio de Ferro" Paulistano: a busca pelo Equilíbrio Instável das Tensões.
}

\author{
Jefferson Ferreira do Nascimento ${ }^{1}$
}

\section{Resumo:}

O presente trabalho visa analisar o impacto das torcidas organizadas de futebol no aumento da violência, especialmente na cidade de São Paulo-SP, Brasil, onde torcedores de três dos mais importantes e populares clubes da América Latina se encontram, apimentados por uma rivalidade marcada pelo equilíbrio na esfera futebolística. Tal análise tem como base uma bibliografia sociológica e antropológica sobre o tema, em especial as produções que tem como pano de fundo o Brasil, a teoria de Norbert Elias, a Lei federal número 10.671, de 15 de maio de 2003 chamada popularmente de Estatuto do Torcedor, a Lei Federal 12.299/2010, o "Novo Estatuto do Torcedor", e visitas na sede de uma das torcidas no ano de 2005 e em jogos de futebol, ora como torcedor comum, ora em companhia de torcedores organizados. Integrando trabalho de campo e bibliográfico foi possível perceber uma modificação na estrutura da violência destas torcidas uma vez que, inicialmente, o Estatuto do Torcedor ampliou a vigilância nos estádios e arredores.

Palavras-chave: Futebol - Torcidas Organizadas - Violência.

\section{Abstract:}

The aim of this work is to analise the impact of organized supporters of soccer in increased violence, especially in São Paulo-SP, Brazil, where fans of three of the most important and popular clubs in Latin America are spiced by a rivalry marked by balance in soccer results. This analysis is based on a sociological and anthropological literature on the subject, especially those productions that is set against the backdrop the Brazil, the theory of Norbert Elias, the Brazillian federal law number 10.671, of May 15, 2003 - popularly called Estatuto do Torcedor, the Brazillian federal law 12.299/10, the "Novo Estatuto do Torcedor", and visits the headquarters of one of Organized Supporters in 2005 and at soccer games, sometimes as comum fan, sometimes in the company of organized supporters. Integrating field work and bilbiography was possible to detect a change in the structure of violence these supporters because, initially, the code of law, Estatuto do Torcedor, expanded surveillance in and around stadiums.

Key-words: Soccer - Organized Supporters - Violence.

\section{Introdução}

O objetivo do presente trabalho é analisar a participação das Torcidas Organizadas e seus membros no aumento da violência e a influência do Estatuto do Torcedor e do Novo Estatuto do

\footnotetext{
${ }^{1}$ Professor EBTT de Sociologia no Instituto Federal de São Paulo (IFSP), Câmpus Sertãozinho. Aluno do Programa de Pós Graduação em Ciências Sociais - Mestrado, da Universidade Estadual do Oeste do Paraná (UNIOESTE), em Toledo. Graduado em Ciências Sociais pela Universidade Estadual de Campinas (UNICAMP) e especialista em História, Cultura e Sociedade.jfnasc@gmail.com
} 
Torcedor nas ações das torcidas organizadas nos estádios, tomando como base a cidade de São Paulo-SP. ${ }^{2}$

A busca é analisar e identificar a participação dessas torcidas na produção da violência, levando em conta o contexto histórico e a situação social do país, deixando clara a diferença desse tipo de violência em relação à criminalidade comum - aquela produzida por motivações econômicas e sociais, que tanto preocupa a população brasileira atualmente.

A escolha do município de São Paulo para cenário deste estudo leva em consideração a concentração de clubes de futebol importantes em termos econômicos, de êxitos esportivos, de número de aficcionados; em suma, em termos de relevância no cenário nacional e internacional. Além disso, em São Paulo tais entidades atingiram um grau maior de profissionalização e autonomia em relação aos clubes que representam. Assim, a escolha é amparada por estudos anteriores, como o de Toledo (2000):

[...] muitas vezes em confronto explícito com dirigentes essas torcidas rapidamente se popularizam, e hoje dominam o cenário das organizações torcedoras, sobretudo na cidade de São Paulo, já que em outros estados o atrelamento aos clubes ainda é verificado como modelo preponderante desse torcer coletivamente. (p.64-65)

Para melhor compreensão é importante ressaltar que os relatos de violência nos remetem aos anos de 1910, inclusive com sequestros de jogadores e danos a meios de transporte, conforme podemos confirmar em Pimenta (2000) na nota número quatro, quando cita o livro O Negro no Futebol Brasileiro: "Atos de violência acompanham o comportamento dos torcedores desde o início dos jogos de competição." Porém, esse modelo de torcidas organizadas ganha força a partir dos anos 1970, quando se desvinculam dos clubes, tornando-se torcedores, contestadores e foco de pressão sobre a administração dos clubes de futebol, marcando uma nova forma de torcer, cobrar e, também uma nova forma de produzir violência. Antes disso, o ato de torcer coletivamente passou por três estágios no Brasil. Até 1920, com os torcedores, provenientes maciçamente, da elite. A segunda por volta dos anos 1940, quando os torcedores passam a acompanhar seus clubes de coração. E a terceira, com o surgimento das torcidas uniformizadas.

\footnotetext{
${ }^{2}$ Este artigo nasce do projeto de iniciação científica "A efetiva participação das Torcidas Organizadas de Futebol no aumento da violência nos Estádios Brasileiros e o seu comportamento após a vigência do Estatuto de Defesa do Torcedor", desenvolvido entre 2004 e 2005, orientado pela Dra. Gilda Figueiredo Portugal Gouvêa, apresentado no XIII Congresso Interno de Iniciação Científica da UNICAMP. Foi atualizado e revisado em 2009 para o trabalho de conclusão da disciplina Teorias Sociológicas Contemporâneas do Programa de Pós-Graduação em Ciências Sociais - Mestrado e Doutorado, da UNESP, câmpus Araraquara, cursada como aluno especial. Em 2015, foi novamente revisado para a apresentação oral "Estigmatização e Contraestigmatização: uma análise sobre torcidas organizadas de futebol e violência", no Colóquio Futebol \& Sociedade organizado pelo Núcleo de Estudos Futebol e Sociedade da Universidade Federal do Paraná (UFPR). Como artigo, é a primeira publicação.
} 
Faz-se necessário também refutar a ideia de que a violência decorrente do futebol se explica unicamente pela lógica simplista do aumento da criminalidade comum que se verifica no país, especialmente após a década de 1980. Como se as paixões e reações estimuladas pelo futebol tivessem relação com a condição socioeconômica, ou com outros condicionantes da mesma natureza. Prova disso são as manifestações violentas decorrentes do futebol em todo o planeta, como o hooliganismo no Reino Unido, na Alemanha e outros países de excelente qualidade de $\mathrm{vida}^{3}$. Por isso, como esfera singular da sociedade merece um estudo particularizado, especialmente encarregado de compreender a origem deste tipo específico de violência, eis aqui a hipótese e o esforço central desta análise.

Para tal empreendimento foram utilizados o método qualitativo e o trabalho de campo. $\mathrm{Ou}$ seja, a análise bibliográfica e a pesquisa em meios de comunicação - tais como sites jurídicos, portais de notícias, revistas, jornais, etc.; e, também, visitas com entrevistas com membros da Torcida Organizada Independente - Subsede Campinas, do São Paulo F.C., em 2005, e o acompanhamento de partidas de futebol, como torcedor comum ou acompanhado por membros de torcidas organizadas no Estádio Cícero Pompeu de Toledo, o Morumbi, na cidade de São Paulo.

\section{O futebol e o despertar das paixões}

A atração exercida pelo futebol independe do nível de desenvolvimento do país e das suas características sociopolíticas, bem como não tem relação direta com a condição socioeconômica dos apaixonados. Para Murphy et al (1994) essa atração se deve à estrutura do futebol. Ou seja, o esporte possui regras e estrutura genérica relativamente simples (facilita a compreensão), custo para prática, comparativamente, baixo, regras e estrutura com alto grau de continuidade e estabilidade, um alto grau de consenso quanto à aplicação das normas e um regulamento que proporciona uma gama de inovações táticas, isso tudo para Murphy et al (1994) facilita a sua difusão pelo mundo e exige uma constante busca pelo aperfeiçoamento dentro desta estrutura rígida e relativamente simples.

Além disso, Murphy et al (1994, p. 8) considera o jogo como um antídoto contra a monotonia do cotidiano, o que causa variações nos níveis de tensão-excitação de expectadores e

\footnotetext{
${ }^{3}$ Essa violência voltou a ser notícia na Eurocopa-2016, realizada na França, com destaque para o enfrentamento entre ingleses e russos e uma série de ações xenofóbicas. O saldo até o momento dessa publicação era de 557 presos.
} 
praticantes, pois as partidas são "[...] simulacros de batalhas travadas com uma bola, autênticas lutas físicas entre dois grupos sujeitos a regras que permitem e despertam paixões ao mesmo tempo em que quase sempre - as controlam".

Por toda essa fascinação causada pelo futebol, fiéis torcedores cultuam seus times e, por vezes, se organizam em grupos: no Brasil, tivemos as torcidas uniformizadas e, atualmente as torcidas organizadas; na Europa, os hooligans; e, na Argentina, os barra-brabas. Nessas organizações grupais reside o problema que neste trabalho trataremos. Assim, buscaremos na teoria das figurações sociais, de Norbert Elias, compreender a violência produzida pelos espectadores de futebol organizados sob estrutura burocrática como consequência, indesejada, da interação social.

\section{A violência nos estádios}

As uniformizadas, surgidas na década de 40, tendo como pioneira a TUSP (Torcida Uniformizada do São Paulo), cujo maior ícone foi a Charanga do Flamengo, que era equipada com instrumentos musicais, eram custeadas pelo clube. Essas uniformizadas eram inspiradas por:

[...] fortes motivações ideológicas da época, cuja sensibilidade política estava alicerçada e difundida em torno das idéias de raça, nação, ordem e, sobretudo, juventude. Período marcado, no plano internacional, pela II Guerra Mundial e o nazi-facismo e, no âmbito nacional, pelo Estado centralizador getulista (Toledo, 2000, p. 63).

Em busca de romper as ligações com o clube para obter a autonomia necessária para pressionar e questionar o mandato de Wadih Helu, presidente do clube à época, surge em 1969 a Gaviões da Fiel (torcida organizada do Sport Club Corinthians Paulista) revolucionando os moldes de organização dos torcedores e, sendo até hoje, a maior torcida organizada do país.

É relevante correlacionar o surgimento dessas instituições torcedoras a um contexto mais amplo de valorização das instituições populares, num período em que os direitos políticos e a cidadania estavam cerceados pelo regime militar. (TOLEDO, 2000, p. 64)

Devemos lembrar que, a violência no futebol na forma de confrontos entre torcedores existe, antes e até mesmo independente, das uniformizadas e organizadas. Confirmando esta tese, Carlos Alberto Máximo Pimenta (2000), relata:

A violência ao redor do futebol não é acontecimento novo e há exemplos na história do futebol brasileiro e mundial (Murphy, Williams e Dunning, 1994:39-70) de atos de extrema violência entre torcedores. O que é inédito é o movimento social de jovens em torno de uma organização que difunde novas dimensões culturais e simbólicas no cotidiano urbano, amoldando o comportamento dos inscritos.

Tal violência certamente é agravada pela diversidade de origens dos vários clubes localizados nos grandes centros. 
Algumas das mais notórias rivalidades no futebol ilustrariam esse ponto: em Lima, há uma rivalidade racial entre o Alianza (pretos e mestiços) e o Universitário (brancos); em Buenos Aires, há uma rivalidade étnica entre Boca Juniors (italianos) e o River Plate (ingleses e espanhóis); no Rio de Janeiro, há uma rivalidade de classes entre o Flamengo (classes trabalhadoras) e o Fluminense (elite); em Glasgow, há uma rivalidade religiosa entre o Celtic (católicos romanos) e o Rangers (protestantes), As equipes são menos conhecidas, mas em Tel Aviv há uma rivalidade política entre o Hapoel, patrocinado pelo Partido Trabalhista e o Maccabi patrocinado pelo partido da direita moderada. (LEVER, 1983, p. 25-26).

Todavia, acompanhamos no decorrer das décadas de 1980 e 1990 o fenômeno mundial de aumento da violência nos estádios das grandes metrópoles. Na Europa, vimos um fenômeno similar, principalmente, na Europa Central e Reino Unido, com maiores destaques para Alemanha e Inglaterra. Com exceção do Reino Unido, cujo enfrentamento também se dava entre equipes locais, nos outros locais citados a violência nos estádios e nos arredores era perceptível, em sua maioria, nos jogos das seleções nacionais e partidas de clubes locais com equipes estrangeiras. Esses torcedores violentos são conhecidos como hooligans e, apesar da atuação deles ser maior na Alemanha e na Inglaterra, toda Europa sofreu nos maiores eventos futebolísticos do período. Na Escócia, a violência nos estádios e arredores também foi marcante na década passada, mas as motivações são de outra natureza. No maior clássico do país entre Glasgow Rangers e Celtics, há também outro ingrediente que "apimenta" o confronto, a rivalidade religiosa. Protestantes torcedores do Glasgow Rangers e católicos do Celtics deixaram a intolerância religiosa entrar nos estádios escoceses (LEVER, 1983).

Podemos, então, perceber que a violência nos estádios não é exclusividade brasileira e podemos perceber também que a violência está presente em diferentes níveis. Desde a rivalidade interna até a rivalidade internacional. Essa rivalidade marca de diferentes formas a violência na vida futebolística dos grandes centros.

No Brasil, os confrontos são protagonizados especialmente por torcidas organizadas de São Paulo, Minas Gerais e Rio de Janeiro - apesar de haver com frequência (e em crescimento) enfrentamentos na Bahia, no Paraná, em Pernambuco. Essas torcidas atuam basicamente nas capitais desses Estados. Na capital fluminense e na capital paulista os casos são mais dramáticos por apresentarem as maiores concentrações de equipes de ponta no futebol nacional. No caso mineiro, a violência é quase que monopolizada pela Galoucura e pela Máfia Azul, maiores torcidas de Atlético Mineiro e Cruzeiro, respectivamente - o que não significa menor violência.

Essa rivalidade é inerente à competitividade do jogo. Os inventores do futebol são pioneiros também nessa violência, há relatos da presença de hooligans no futebol desde o fim do 
século XIX, ou seja, desde a invenção do futebol como hoje conhecemos; ainda na Inglaterra, nos anos 1960 vários grupos como os mods, rockers, teddy-boys e, mais adiante, os skinheads viram no futebol um espaço importante para extravasar suas formas de protestos (TOLEDO, 1996).

Houve uma tendência na metade da década de 1990 que discutia se as Torcidas Organizadas seriam os hooligans brasileiros, porém essa tendência foi abafada pelas comprovações de várias diferenças entre torcedores organizados e hooligans. Como podemos constatar no livro de Toledo (1996), os hooligans não usam símbolos ou vestimentas que os identifiquem como grupo, apesar de serem, neste sentido, organizado com poder central. Além disso, esses torcedores possuem projetos ideológicos, muito próximos de movimentos como o dos skinheads, por exemplo, cujo enfrentamento diante das instituições sociais é mais ostensivo.

Assim, na década de 1990 as Torcidas Organizadas passaram a ganhar espaço na mídia como produtores de violência e "massa de manobra política" financiada por dirigentes, sendo minimizada sua importância como forma de agrupamento de iguais (exemplos da torcida da terceira idade Bengala Azul e de homossexuais, como a Fla-gay), exatamente quando um novo perfil de torcedor passa a ser exaltado e modelado, tanto pela mídia, como pelo clube - o sóciotorcedor.

Esse novo perfil de torcedor passa a ser a representação ideal da presença do espírito capitalista no futebol - é o torcedor consumidor. Para Toledo (2000) o sócio-torcedor possui os requisitos necessários para a transição da condição genérica do torcedor comum ou organizado para a de consumidor esportivo. Esta tendência que se acentua a partir da segunda metade da década de 1990 pode ser uma das várias explicações para a forma de abordagem predominante na imprensa sobre as torcidas organizadas como produtores e difusores de violência.

Indiscutível, porém, dizer que a passagem das Torcidas Uniformizadas para Torcidas Organizadas tornou, sim, mais dramáticos os confrontos nos estádios e arredores, fazendo, inclusive, vítimas fatais, por isso a presente análise não cuida apenas de acusar essas agremiações, mas analisar tais torcidas como reflexo do campo social que estão inseridas. Assim a busca para a compreensão deste caso específico, envolve uma avaliação do comportamento dos atores sociais perante a adaptação dos quadros coercitivos legais, dos meios de prevenção a novas formas de violências, que “[...] mostra um entrelaçamento de inúmeros fatores que são concorrentes, colocando os centros urbanos, as relações entre os indivíduos e os grupos sociais em xeque" (PIMENTA, 1997, p.20). 
É preciso, portanto, isolar da violência do futebol a violência das torcidas organizadas, já que segundo Pimenta (1997, p. 52):

[...] a violência produzida na esfera futebolística não permanece apenas no âmbito das torcidas organizadas; ela está presente dentro do campo de jogo, nos bastidores, nas relações mercadológicas clube/jogador, clube/torcedor, clube/empresa, etc.

E, além disso, tratar essa violência produzida pelas Torcidas Organizadas tanto na ação explícita, como no campo legal. Pois, estas instituições são organizadas sob uma estrutura burocrática, de direito privado, teoricamente sem fins lucrativos, que surgiram das torcidas uniformizadas na década de 70, com o intuito de pressionar clube e atletas para a obtenção de melhores resultados (TOLEDO, 1996). Sendo assim, com o aumento da presença e influência nos estádios, elas “[...] estabeleceram novos padrões de comportamento aos seus membros, que buscavam auto-afirmação através da vestimenta, da identificação grupal e da falsa superioridade de um grupo sobre o outro.”(PIMENTA, 1997, p.77)

\section{As organizadas, o futebol, os jovens e o ego-nós.}

Norbert Elias salienta que "Os grupos humanos parecem ter o estranho prazer de afirmar sua superioridade sobre os outros, sobretudo se ela foi obtida por meios violentos" (ELIAS, 1998, p.17). Este aspecto emocional, segundo ele, possibilita uma gratificação narcisista, já que parte da autoestima individual depende do sucesso ou fracasso do grupo aos quais pertencem ou identifiquem-se.

Neste sentido, a questão que se erige está na discussão do segmento envolvimento/alienação, já que Elias (1998) defende que ninguém deve ser totalmente envolvido, nem totalmente alienado, isto quando se fala do comportamento normal de um indivíduo adulto, variando entre esses pólos o tipo de comportamento. Porém, em certos grupos o tipo de comportamento/pensamento tende para um dos pólos, o que seria danoso para vida social.

$\mathrm{Na}$ verdade, a diversidade de origem dos vários clubes nos grandes centros urbanos pode ser um catalisador, e a existência de violência entre torcedores antes das organizadas não invalida nossa tese a seguir, pois os torcedores investem em um clube sua paixão, devoção e honra, e a identificação também age sobre a autoestima e não apenas a participação (ELIAS, 1998). O desprezo pela ordem social estabelecida é, na verdade, fruto da distorção causada na percepção de qual comportamento é socialmente aceito, devido ao excesso de envolvimento dos indivíduos em um grupo social - neste caso, Torcidas Organizadas. 
Quanto mais forte a influencia das formas envolvidas de pensamento e, assim, da inabilidade para distanciar-se das atitudes tradicionais, tanto mais forte o perigo inerente à situação criada pelas atitudes tradicionais das pessoas, dirigidas aos outros e a si mesma. (ELIAS, 1998, p.22)

E, para ser mais ilustrativo, vejamos a seguir:

A notável propensão que as pessoas apresentam para projetar parte de sua auto-estima individual nas unidades sociais específicas, às quais estão ligadas por fortes sentimentos de identidade e de participação, é uma das raízes dos perigos que os grupos humanos constituem uns para os outros. (ELIAS, 1998. p.19)

Mostrando a eficácia de Elias para o estudo das torcidas organizadas, Toledo (1996) afirma:

Participar desses agrupamentos torcedores implica legitimar, vivenciar e aceitar uma série de regras, comportamentos rituais, investimentos simbólicos, tempos, linguagens, que transcendem os padrões normais e, em grande parte, socialmente aceitos daquilo que se entende por torcer para times de futebol (p.119).

Para Elias (1994a), a estrutura emocional do homem tem importância decisiva para o funcionamento das sociedades e dos indivíduos, e a agressividade seria uma função pulsional dentro da totalidade de um organismo. De tal modo que a mudança na agressividade provoca mudanças na estrutura da personalidade como um todo. Sendo assim, os fatos lamentáveis que se tornaram comuns a partir de meados da década de 1990 apontam os grupos de torcedores como um grupo social onde a liberação da pulsão agressiva é permitida, por vezes, exaltada e, consequentemente, a personalidade dos indivíduos que constituem esse grupo é influenciada pela falta de alienação que conduz o amor-próprio ao narcisismo. Isto porque, o ego-humano é constituído pelo ego-eu e ego-nós, residindo na predominância do ego-nós a raiz do problema (ELIAS, 1994b). Por isso:

Sua auto-representação, característica de seu desenvolvimento cognitivo e narcisista, é com freqüência uniformemente boa, enquanto rivais ou inimigos tendem, segundo sua ótica, a não ter nenhum mérito, sendo completamente maus. (ELIAS, 1998, p.20).

É importante ressaltar que não se trata de desvio de personalidade fomentado pelo pertencimento às torcidas organizadas. Trata-se de indivíduos comuns, que, em sua maioria, mantém uma vida coerente com as normas sociais, desempenham seus papéis sociais de acordo com a expectativa da sociedade. Mas, encontram no âmbito do futebol, notadamente nas torcidas organizadas um espaço onde a falta de alienação em relação aos valores grupais conduz ao narcisismo. Trata-se, portanto, de um espaço específico da vida social onde a liberação da pulsão agressiva não é condenada.

Outro fator que contribui com essa interpretação é que, para Pimenta (1997), o fato de a maioria dos filiados das “Torcidas Organizadas" possuírem entre 13 e 22 anos mostra que essas 
torcidas são espaços para as manifestações, seja ela individual ou coletiva, onde a violência promovida por elas denota a busca do desenvolvimento da personalidade de seus membros.

Podemos perceber que, ainda que as lideranças não estimulem publicamente a violência, a Torcida Organizada provoca uma alteração na percepção dos indivíduos sobre qual comportamento é socialmente aceitável e esperado em nome do amor por um clube, isso devido ao envolvimento excessivo de seus membros.

Observemos:

Ao mencionar o prazer que as pessoas experimentam com a sensação de que o grupo a que pertencem é superior aos outros, abordamos o aspecto emocional das relações entre os grupos e os perigos a elas inerentes. Parece que parte da auto-estima dos indivíduos pode direcionar-se a um dos grupos com que se identifiquem, a maioria deles às nações ou à outros grupos de sobrevivência. $\mathrm{O}$ sentimento da superioridade do grupo parece proporcionar a seus membros imensa gratificação narcisista (ELIAS, 1998, p.17).

Percebemos aqui que a necessidade de afirmação como grupo superior faz com que elejam os demais grupos como rivais, pois o futebol é responsável pelo afloramento das tensões, como os demais esportes de espectadores e, da mesma forma, proporcionam uma arena de enfrentamento, às vezes, até com origens políticas, econômicas e sociais, como percebeu Helal (1990), assim temos na discussão sobre torcidas organizadas uma multiplicidade de fatores que se complementam e torna complexa a análise do problema.

Nesta multiplicidade de fatores, percebemos que os grupos de pessoas, neste caso as torcidas:

[...] com brilhos nos olhos e um aceno de íntima compreensão, asseguram-se mutuamente o quanto são maiores, melhores e mais fortes do que algum grupo em particular, ou quem sabe mesmo, do que os demais grupos humanos. Secretamente ou não, todos possuem um vocabulário correspondente de difamação, dirigido aos outros. (ELIAS, 1998, p.18).

É por esta ótica que cantos, gritos de guerra, discursos e símbolos são parte constitutiva de um arsenal de recursos utilizados para motivar e satisfazer seus pares, ao mesmo tempo, que desafia e difama os demais grupos, considerados, por esses indivíduos, rivais.

Esta constante busca pela supremacia do grupo, motivada pela busca da satisfação individual, seria uma espécie de busca violenta pelo equilíbrio instável das tensões, que ocorre, por exemplo, na dominação de uma classe sobre a outra (ELIAS, 2001); ou seja, por serem grupos concorrentes estas torcidas organizadas se confrontam em busca de efetivar uma dominação; afirmar a superioridade de uma sobre a outra é impor uma dominação e, por conseguinte, estabelecer o equilíbrio instável das tensões. Além disso, temos a necessidade de 
afirmação como grupo superior para a satisfação individual e a reafirmação ou correção da superioridade estabelecida de modo não violento no campo de jogo, que também é parte integrante da autoestima individual, já que os torcedores investem sua paixão, devoção e honra em seu clube do coração.

Em suma: pela correção ou reafirmação da superioridade estabelecida no campo de jogo, de forma desportiva, e pela importância do sucesso do grupo para a autoestima individual, a busca pela superioridade, que determinaria o equilíbrio instável das tensões que, por vezes, se dá num enfrentamento violento, não pode ser reduzido a simplesmente a banditismo. Pois, vimos a multiplicidade de fatores que agem na regulamentação da vida social.

Sendo assim, o grande número de confrontos, deve-se também ao grande número de equipes rivais no Brasil, por isso, como toda análise da realidade social, supervalorizar um fator e desvalorizar outros nos leva a uma análise simplista. Neste sentido, num estudo sobre a figuração estabelecidos-outsiders, Elias (2000) afirma:

[...] a capacidade de estigmatizar diminui ou até se inverte quando um grupo deixa de estar em condições de manter seu monopólio das principais fontes de poder existentes numa sociedade e de excluir da participação nessas fontes outros grupos interdependentes - os antigos outsiders. Tão logo diminuem as disparidades de força ou, em outras palavras, a desigualdade do equilíbrio de poder, os antigos outsiders, por sua vez tendem a retaliar. Apelam para a contra-estigmatização. (p.24)

Mas, no caso das torcidas organizadas, não há e não houve este monopólio e a figuração estabelecido-outsiders só existe na auto representação que estes indivíduos fazem do grupo que pertencem e na visão de inferioridade que possuem dos demais grupos. Ou seja, cada grupo se considera estabelecido, apesar de não estar efetivada essa relação na sociedade, e enxerga os outros como grupos inferiores - outsiders - ainda que nenhum destes grupos aceitem esta condição.

Deste modo, o grupo que se enxerga estabelecido tende a atribuir aos grupos que ele próprio considera outsiders:

[...] as características 'ruins' de sua porção 'pior' - de sua minoria anômica. Em contraste, a auto-imagem do grupo estabelecido tende a se modelar em seu exemplar, mais 'nômico' ou normativo -na minoria de seus melhores membros. (ELIAS, 2000, p.23)

O conflito então se dá na busca que cada um dos grupos empreendem para afirmar a sua condição de estabelecido, negando, desta forma, a condição de outsiders que os demais grupos lhe atribui. Esta busca pelo equilíbrio instável do poder se dá, neste caso, através do 
enfrentamento violento, e da intensificação da constante estigmatização e contraestigmatização, o que demonstra que os diferenciais de poder ainda não estão afixados.

As visitas aos estádios permitiram observar a presença constante de drogas, especialmente em locais destinados aos organizados, sugerindo uma relação estreita entre criminalidade comum e essas torcidas organizadas. O que tende a deixar mais drásticos os confrontos, já que a apreensão de drogas, armas e bombas de fabricação caseira não são casos isolados como os noticiários comprovam. Em visita a subsede da Torcida Independente de Campinas ouvimos de seus membros que a violência diminuiu nas proximidades dos estádios, em função do policiamento mais intenso. Porém, as brigas continuaram ocorrendo em bairros, especialmente em áreas periféricas.

Ainda nessa visita, ouvimos da Direção da subsede da referida torcida que existe um trabalho interno para tentar barrar a violência: os diretores se reúnem com o Ministério Público e com a Polícia Militar para garantir a autorização de funcionamento da torcida e as fichas de associados são entregues e atualizadas junto a Polícia. Mas, conforme a avaliação dos diretores, convencer os membros a não usar violência é difícil e quando ocorre confronto a tendência é de participação de pessoas dos mais variados perfis e condições socioeconômicas - não é, portanto, uma atividade de membros isolados de um determinado perfil social. Quando questionados sobre a existência de marginais infiltrados no interior da Torcida, os diretores afirmaram ser difícil analisar a vida de cada associado, e reiteraram que a torcida cumpria seu papel de manter a polícia atualizada em relação aos filiados.

De acordo com os membros, a violência existe sistematicamente na periferia de São Paulo, mas é pouco noticiada como violência entre torcidas. A preocupação de cada membro era a de mostrar a legitimidade de suas ações, em detrimento de uma postura condenável das outras instituições, o que confirma a tese de Elias sobre a relação de estigmatização e contraestigmatização, também verificável nos cantos entoados pelos membros das organizadas.

\section{A confusão: violência entre torcidas e criminalidade comum}

Vejamos:

Por que um torcedor é capaz de matar outro? Sigmund Freud o chamaria de narcisismo das pequenas diferenças. Também poderíamos chamá-lo de teoria do inimigo mais próximo. O futebol, temos que admitir, é um eficaz caldo de cultivo da lógica tribal. E das lógicas inter tribais às múltiplas possibilidades da representação da guerra, há, de fato, uma margem muito estreita. (VARGAS apud AGOSTINO, 2002) 
Isso nos permite ver que o problema não é de origem socioeconômica, mas da organização do futebol, das paixões que essa estrutura desperta. Por outro lado, há a agravante do acirramento da rivalidade proporcionado pelo aumento do profissionalismo, que culminou também com a existência das torcidas organizadas, pois, de acordo com Toledo (2000), "grupos de torcedores mobilizaram-se em torno de instituições mais alternativa de participação no futebol profissional" (p.64).

A despeito desta percepção, a visão de João Paulo de Jesus Lopes, ex vice presidente de futebol do São Paulo F.C., da mídia e de vários envolvidos no combate à violência entre os espectadores de futebol, como Fernando Capez, promotor responsável do assunto na década de 1990, é de que esta violência tem as mesmas raízes da criminalidade comum. Lopes, ao ser entrevistado via telefone, relacionou a violência entre torcidas com a condição social do Brasil, onde percebe a depreciação das condições sociais do brasileiro a partir dos anos 1980 e o, consequente, aumento da violência.

Por um lado, a análise tem certa precisão porque, com a precarização das contas públicas, iniciado em 1978, quando ocorreu o aumento das taxas de juros internacionais e se acentuaram as tensões sobre o dólar nos mercados cambiais, houve um crescente endividamento do Brasil que, combinado com a excessiva exposição dos bancos ao risco-Brasil, determinaram o encurtamento dos prazos dos empréstimos e financiamento.

Entretanto, relacionar esse processo de vulnerabilização socioeconômica e o agravamento das tensões entre as torcidas é reconhecer a realidade social e simplificar os determinantes sociológicos. Pois, a passagem de Torcidas Uniformizadas para Torcidas Organizadas ocorre a partir de 1969 - fundação da Gaviões da Fiel, passando por 1972 (passagem de TUSP - Torcida Uniformizada do São Paulo - para Torcida Independente) e se completando em 1983, quando o triângulo é fechado com o surgimento da Mancha Verde (resultado da fusão das torcidas organizadas Império Verde, Inferno Verde e Grêmio Alviverde), onde os três principais clubes de São Paulo passam a ser representados de forma que as torcidas, em número e influência passa a mais ou menos se equivalerem.

Desta forma, o fechamento do triângulo das mais influentes torcidas organizadas de São Paulo, coincide com o fim do financiamento, em 1982, após a moratória mexicana, da depreciação das contas públicas em moeda estrangeira, por bancos comerciais "internacionalizados" - o fim do chamado "ajustamento voluntário". Quer dizer, o fechamento do 
triângulo das torcidas paulistanas ocorre ao mesmo tempo em que os sinais de crise aparecem no Estado brasileiro e nas riquezas privadas, por isso, a impressão de que a violência entre torcidas organizadas é fruto da depreciação das condições socioeconômicas.

No entanto, pouco se fez, mesmo de acordo com esta visão generalizante de um problema meramente socioeconômico. Fica claro pelo exposto que a violência das organizadas não é única e exclusivamente determinada por criminosos infiltrados, há também uma violência intrínseca a concorrência entre esses grupos. É inegável que a proximidade com o crime agrava a violência entre os espectadores de futebol e, ao mesmo tempo, dissemina suas raízes dentro da sociedade.

Pois, criminosos, muitas vezes, disponibilizam armas para esses jovens, disseminam ensinamento sobre confecções de bomba e transforma a batalha entre as torcidas numa guerrilha urbana, dando a ela, contornos mais graves do que o tolerável.

\section{A violência das organizadas e o aparato legal}

É necessário analisar a articulação do aparato legal, ou seja, as medidas que o Estado toma para coibir essa violência. Na Europa, o monitoramento dos estádios consistiu no primeiro passo, depois houve a edição de uma lista de indivíduos envolvidos em incidentes nos estádios e arredores, os indivíduos cujos nomes constarem nessa lista são proibidos de entrar nos estádios por um tempo determinado, variando de três meses ao resto da vida. No Brasil, a mais significativa medida foi, sem dúvida, estender ao esporte o Código de Defesa do Consumidor, com o chamado Estatuto de Defesa do Torcedor - Lei 10.671 de 15 de maio de 2003 - que equipara o torcedor ao consumidor e os responsáveis pela competição e jogos são equiparados ao fornecedor. Assim, entre outras medidas o Estatuto regulamenta o monitoramento interno e externo dos estádios com capacidade superior a 20 mil espectadores e a chamada "responsabilização objetiva". O que seria a responsabilidade objetiva?

Seria a "responsabilidade independente da existência de culpa", conforme estabelece a lei. Para melhor explicar, tomemos por base o artigo $3 .^{\circ}$, onde se exclui a responsabilidade do fornecedor de serviço apenas quando fica provado que, prestado o serviço, o defeito inexiste, ou trata-se de culpa exclusiva do consumidor ou de terceiro. Ou seja, perante o Estatuto:

Como se observa até o momento, é certo que o evento desporto - Futebol - é um produto, sendo o fornecedor, a entidade responsável pela organização da competição bem como a entidade de prática desportiva detentora do mando de jogo; e o consumidor, o torcedor. (SESMA, 2003) 


\section{Entretanto:}

Em análise preliminar, devemos distinguir a responsabilidade pelos danos causados aos torcedores decorrentes do próprio evento em si, por exemplo, superlotação, condições precárias dos estádios etc, da responsabilidade pelos prejuízos que decorram da falta de segurança, por exemplo, um torcedor agredido por outro de torcida rival ao final da partida, que foi atribuída pela nova lei às entidades e seus dirigentes de forma objetiva e solidária. Na primeira hipótese, pela própria aplicação do já consagrado Código de Defesa do Consumidor, recaem sobre os promotores do evento e o proprietário do estádio. (SESMA, 2003)

Uma vez que este era o principal regulamento dos direitos do espectador nas competições esportivas no país, ficava clara a lacuna da responsabilização dos próprios torcedores que produzem a violência. Afinal, tudo se reduzia, para os legisladores, a uma questão de consumidor e fornecedor, sem considerar a peculiar relação entre torcedores e futebol.

Para se eximirem da responsabilidade objetiva os dirigentes e responsáveis pelos principais estádios acataram a o dispositivo que obriga a instalação do sistema de monitoramento interno e externo nos estádios com capacidade superior a 20 mil espectadores. Com efeito, a violência caiu significativamente nos estádios e arredores, quando ela acontecia bastava ao mandante identificar os agressores. Entretanto, uma vez identificados, estes agressores não sofriam punições sistemáticas e exemplares, já que na legislação não havia um código de lei que regulamentasse a conduta dos torcedores, é, principalmente, por isso, que o JECRIM (Juizado Especial Criminal) instalado nos estádios paulistanos nos principais clássicos, e a solicitação da Polícia Militar para que as torcidas entreguem e atualizem o registro das fichas cadastrais (contendo foto, identidade e endereço) dos membros de cada torcida organizada, naufragaram. Pois uma vez identificado o que fazer com os envolvidos em atos de violência?

O "Novo Estatuto do Torcedor" alterou o Estatuto do Torcedor, pois criminalizou várias condutas e incrementou penas de vários atos já criminalizados no Estatuto do Torcedor em 2003, por exemplo, em seu artigo 39:

Art. 39. O torcedor que promover tumulto, praticar ou incitar a violência, ou invadir local restrito aos competidores ficará impedido de comparecer às proximidades, bem como a qualquer local em que se realize evento esportivo, pelo prazo de três meses a um ano, de acordo com a gravidade da conduta, sem prejuízo das demais sanções cabíveis. (BRASIL, 2010)

Após o Novo Estatuto do Torcedor, as alterações realizadas no Estatuto do Torcedor foram: a Lei $12.663 / 2012$ e a Lei 13.155/2015. A primeira, com foco exclusivo na Copa do Mundo e na Jornada Mundial a Juventude, regulamentou no Estatuto do Torcedor o uso de bandeiras e outros instrumentos de torcidas. A segunda alterou o Estatuto do Torcedor no que diz 
respeito a princípios e práticas de responsabilidade fiscal e financeira e de gestão transparente e democrática para entidades desportivas profissionais de futebol; instituiu parcelamentos especiais para recuperação de dívidas pela União, cria a Autoridade Pública de Governança do Futebol APFUT; dispôs sobre a gestão temerária no âmbito das entidades desportivas profissionais; cria a Loteria Exclusiva - LOTEX. Ou seja, nenhuma alteração sistemática ocorreu no que diz respeito a prevenção e a punição relativas à violência no futebol após 2010, com o Novo Estatuto do Torcedor.

Entretanto, mesmo com o Novo Estatuto, há uma espécie de sentimento coletivo de impunidade, pois as punições previstas na Lei 12.299/2010 não foram exemplarmente aplicadas. Isso pode ser verificado nas pesquisas em meios de comunicação. A reportagem da BBC Brasil (MENDONÇA, 2015) fala em "jogo de empurra" e "falta de punição aos envolvidos". O Portal Trivela advoga que "Leis existem, mas o Estado precisa agir para coibir a violência" (LOBO, 2014).

Dito isso, voltemos à Norbert Elias, que chama a atenção para um processo civilizador que, através de normas impostas, desperta a vergonha e a repugnância nos indivíduos de algumas atitudes outrora comuns. O gosto pela violência deliberada e o prazer da dor do seu oponente foram gradualmente condenados e, assim, reprimidos por uma visão condenatória da sociedade. Esse processo civilizador foi sendo moldado por normas impostas e tornadas necessárias pelo aumento da dependência dos indivíduos entre si, determinado pela divisão das funções na divisão social do trabalho.

Neste sentido, o que se esperava do Estatuto do Torcedor e do Novo Estatuto do Torcedor era que eles conseguissem agir desta forma, ou seja, estes estatutos, como conjunto de normas coercitivas, deveria iniciar o despertar nos torcedores desse controle da função pulsional "agressividade", até que esse controle fosse internalizado. Uma vez internalizado, esse controle se daria não só pela vergonha e repugnância, mas também porque, ao longo desse processo iniciado com o Estatuto do Torcedor, o embate violento passaria a ser desprezado. Ou seja:

A compulsão real é a que o indivíduo exerce sobre si mesmo, seja como resultado do conhecimento das possíveis consequências de seus atos no jogo de atividades entrelaçadas, seja como resultado de gestos correspondentes de adultos que contribuíram para lhe modelar o comportamento em criança (ELIAS, 1993, p. 200).

Fala-se aqui sobre um processo civilizador que já está num estágio bem avançado nas sociedades ocidentais atuais, mas cabe ressaltar que há diferenças na estrutura social dos grupos 
que compõem a sociedade e da sociedade como um todo. Esse processo civilizador em curso nas sociedades ocidentais, não penetra igualmente em todos os grupos e campos que compõem essa sociedade. Neste sentido, não penetraria na relação entre as torcidas organizadas de futebol. Quer dizer, o mesmo indivíduo membro de uma torcida organizada que recorre à violência em algum momento, mantém regulação constante de seu comportamento na vida cotidiana. Podemos recorrer à metáfora usada por Elias (1993, p.197), sobre as diferentes “estradas": as "estradas interioranas de uma sociedade simples" e as "ruas principais de uma grande cidade na sociedade complexa de nosso tempo" não devem ser diferenciadas apenas por dimensões temporais (de sociedades simples no passado e complexas no presente). Em uma sociedade complexa, há grupos e campos distintos, vivenciando diferentes espaços-tempo e, por isso, uma mesma pessoa transita nessas diferentes vias e, se pela imprevisibilidade das "estradas interioranas", mantém uma "prontidão constante para a luta" não necessariamente isso significará a ausência de autocontrole nas questões cotidianas. Não se trata, enfim, de "civilizados" e "incivilizados", mas de campos distintos, com regras distintas e exigência de papéis distintos na vida social. Nas palavras de Elias (1993, p. 211):

Esse movimento da sociedade e civilização, porém, certamente não segue uma linha reta. No movimento global observam-se repetidas vezes contramovimentos maiores ou menores, nos quais os contrastes na sociedade e as flutuações na conduta de indivíduos, suas explosões afetivas, tornam a aumentar.

Com as respostas obtidas na análise bibliográfica fomos buscar constatação ou negação dessas teorias. Em primeiro, lugar fomos a busca de opiniões sobre o Estatuto do Torcedor e sobre as medidas necessária para a realização desses eventos com João Paulo de Jesus Lopes, exdiretor de planejamento e ex-vice presidente do São Paulo F.C, que devido a sua função esteve por anos em constante contato com o Estatuto e as autoridades. E, com essa entrevista foi possível, confirmar as lacunas do Estatuto: para Lopes o Estatuto está funcionando, ainda seja falho no que diz respeito a responsabilização criminal. Nas palavras dele:

O Estatuto do Torcedor está funcionando, prova disto é que quando é feita a solicitação às autoridades e elas, de uma maneira geral, cumprem essas solicitações têm-se um policiamento mais rígido, um trânsito fluindo melhor. Não a contento, pois muitas autoridades não estão cumprindo as solicitações a contento, e muitos clubes não fazem o planejamento adequado, mas fazem alguma coisa, e isso melhorou o nível de segurança. A melhora é mais sentida nos estádios que receberam um sistema de monitoramento adequado. Aqui no Morumbi, por exemplo, o sistema de monitoramento possui um sistema de TV que capta imagens internas e nos arredores do estádio, possibilitando que a polícia tome conhecimento imediato de qualquer situação, o que facilita a tomada de providência. 
Em relação ao Novo Estatuto do Torcedor, apenas a crítica do jurista Luiz Flávio Gomes ilustra bem o panorama:

O legislador brasileiro, que é muito sensível a esse tipo de demanda e de pressão, sobretudo diante de cada emergência penal, em lugar de incentivar uma séria política de prevenção da violência, aciona sua "fábrica de leis", que é em regra emocional, irracional e desproporcional, "vendendo-as" como "remédio" para o problema. [grifo meu] (GOMES, 2010)

\section{Conclusão}

Observemos:

O futebol, sobretudo para estes torcedores organizados, não consiste tão- somente num momento de fruição e entretenimento, como se fosse uma mercadoria consumida em algumas poucas horas. Ao contrário, ele é parte constitutiva na elaboração de um estilo de vida próprio. Ao assumirem preferências pelas cores do coração, por símbolos e marcas de cada Torcida Organizada, estes indivíduos referendam condutas específicas diante dos outros grupos, na escola, no trabalho e na vida própria. (TOLEDO, 1996, p.114).

Podemos concluir desta pesquisa, portanto, que as torcidas organizadas estão ligadas ao aumento da violência. Mas, cabe salientar, que existe uma violência inerente à concorrência entre grupos equivalentes em um campo onde há regras pouco claras para a imposição de uma hegemonia. Como teorizava Elias (1993, p.207-210), o processo civilizador avança pela difusão da pressão pela previdência e autocontrole, ou seja, pela "necessidade de subordinar emoções momentâneas a objetivos mais distantes", o que, de fato, ocorre em um cenário onde a competição se desenvolve mediante regras claras ou mediante a dominação evidente de um grupo - como no jogo de futebol em si, mas na relação entre torcidas organizadas, a realidade é outra.

No âmbito dessas torcidas, a fonte de satisfação proveniente da coragem e vontade de luta somada à lealdade de seus companheiros é fruto do excesso de envolvimento que esses adolescentes e/ou jovens adultos possuem em relação ao seu grupo. Isso tudo aliado à necessidade de se tornar estabelecido e, por conseguinte, condenar o rival à condição de outsider seria a forma de estabelecer o equilíbrio instável de poder e de satisfazer a sua autoestima, que por estarem excessivamente envolvidos, dependem em grande parte do sucesso do grupo a que pertencem (ou seja, o ego-nós predominando e sendo uma das raízes do problema).

A predominância de jovens de 13 a 22 anos pode ser um complicador, pois este é um período de constituição da personalidade, o que pode dificultar o equilíbrio entre envolvimento e alienação e, consequentemente, tornar mais trabalhoso ainda escapar da autoimagem de estabelecido e da crença de que os outros grupos são outsiders. Ficando distorcida a ideia do que 
é bom e ruim, normal e anômico, concorrente e inimigo. Dessa forma, a opção pela violência passa a ser aceita internamente com mais facilidade.

Porém, é importante afirmar que a violência entre torcedores não é única $\mathrm{e}$ exclusivamente promovida por torcedores organizados, mas por seu envolvimento ter acentuado a dramaticidade da violência, torna-se necessário estudar o caso.

Esperava-se, portanto, que o Estatuto de Defesa do Torcedor começasse a funcionar, quer dizer, atuando como um conjunto de normas coercitivas desencorajasse gradativamente a busca pelo confronto violento, tornando o resultado do campo o definidor deste equilíbrio instável de poder (ainda que momentâneo), impedindo que a violência fosse um meio de contraestigmatização. Ou melhor, impedindo que o confronto entre esses torcedores organizados fosse uma forma de corrigir ou de reafirmar o que foi conseguido no campo de jogo.

E, desta maneira, o futebol continuaria sendo alegria e decepção, tensão-excitação, rivalidade e lealdade, força e habilidade, desafio físico e autocontrole, jogo de equipe e individual, mas tudo passaria a ser definido apenas por intermédio da bola dentro do campo e, exclusivamente, assim as diferenças seriam estabelecidas. Nada disso ocorreu, a vigilância melhorou, sem dúvidas. Mas não há uma regulamentação que puna os envolvidos em violência, fazendo com que, na prática o Estatuto do Torcedor defenda os interesses dos torcedores enquanto consumidores. Apenas isso!

Nesse mesmo sentido, o Novo Estatuto do Torcedor apresentou avanços na caracterização de crimes e de penas relativas à violência no futebol, mas nenhuma política séria de prevenção acompanhou a criação nem do Estatuto (2003), nem do Novo Estatuto do Torcedor (2010). Nas palavras do sociólogo Maurício Murad: “Tirar bandeirão, proibir organizadas, fazer torcida única não vai resolver. Precisa atacar o problema. Precisa ter um plano estratégico nacional para resolver isso, que reúna todas as entidades envolvidas" (MENDONÇA, 2015). Nos últimos anos, com a dificuldade de aplicação das punições previstas, a insegurança nos estádios brasileiros permanece. E a opção escolhida foi a elitização: pesados investimentos para modernização dos estádios - visando a Copa do Mundo, as chamadas arenas, e a elevação dos preços dos ingressos.

Fica, portanto, através do testemunho e das evidências, difícil acreditar que essa relação entre criminalidade comum e a violência inerente à estrutura grupal não se confunda e se complete. Então o discurso vigente desde 1995 sobre a violência das torcidas não é totalmente falho, mas falta atitude. Na verdade, assumir essa relação e aceitá-la publicamente, coloca a 
impressão de que se trata de um problema que não se resolve sem mudanças radicais nas condições socioeconômicas. Fica ainda mais difícil acreditar que se trata apenas de identificar os ditos "maus elementos" e que boa parte das armas apreendidas com membros de torcidas e as que, possivelmente, ainda estão em poder dessas pessoas não seja facilitada pela relação com a criminalidade comum. Acreditar que a posse de armas com esses indivíduos seja fato isolado seria menosprezar o problema.

Claramente a falta de medidas preventivas para quebrar essa perigosa relação, demonstra um desconhecimento da origem da violência, daí a relevância do presente estudo. Além disso, há pouca ação efetiva e o discurso oficial dos envolvimentos aponta certo comodismo: no geral, não admitem que essa violência não é unicamente devido à infiltração de criminosos e nem admitem o quão vago é a generalização das causas dessa violência como um problema de origem socioeconômica. Para piorar, nem mesmo as causas que são admitidas são efetivamente combatidas.

Aliás, essa melhora, segundo o que captamos nos depoimentos, causou, por algum tempo, uma acomodação por parte das autoridades. Pois, a violência dos espectadores de futebol não foi reduzida ou banida, mas migrou para a periferia, estações de trens, ponto de ônibus e afins. Isso gerou um discurso das autoridades que prega a dificuldade em combater esta violência devido a sua dispersão. Essa migração e dispersão da violência produziram uma falsa sensação de melhora, devido à dificuldade de se noticiar e de monitorar o que ocorre perifericamente nos grandes centros. E, mesmo essa sensação de melhora, caiu por terra a partir de 2009, tendo como marco o Campeonato Brasileiro de 2013 com diversos acontecimentos violentos envolvendo torcidas organizadas e Atlético-PR, Atlético-MG, Corinthians, Cruzeiro, Goiás, São Paulo e Vasco da Gama - afinal dez anos de Estatuto do Torcedor e quantos torcedores foram realmente punidos? Quais foram os planos de segurança das competições nacionais depois de 2010 ?

Além disso, a forma como a mídia veicula as informações referentes às torcidas vende-se impressão de um problema unicamente de criminalidade comum, facilitando a crença de que a solução depende da melhora socioeconômica do país. Não exatamente! O problema é mais amplo, porém a resolução de apertar o cerco, com a finalidade de barrar a infiltração do tráfico nessas entidades, tornaria menos dramática a cena. Tornando, apenas, eventual e físico o embate entre as torcidas organizadas. Suficiente? Obviamente não, mas satisfatório, pois como sabemos o tráfico é um multiplicador de problemas sociais. 
Portanto, a maior atenção sobre essas entidades, a fim de barrar essa relação promíscua, seria mais eficaz de que a proibição destas entidades, pois além de inconstitucional, já tivemos uma experiência frustrada neste sentido, na década de 1990. Assim, a atualização constante das fichas cadastrais dos membros dessas entidades foi um passo importante, mas apenas inicial. Logo, a maior vigilância sobre as entidades, incluindo revistas temporárias nas sedes, e a intensificação na implantação das medidas de segurança previstas no Estatuto do Torcedor, aliado à aplicação das punições previstas pelo Novo Estatuto do Torcedor para os responsáveis pelos confrontos violentos poderia ser uma forma de despertar nos torcedores esse medo da punição, como início imposto do controle da função pulsional "agressividade", até que esse controle fosse internalizado. Não só pelo medo da punição, mas também porque, ao longo desse processo o embate violento passaria a ser desprezado.

Por outro lado, é importante lembrar que exceções como a Torcida Bengala Azul, do A.D. São Caetano (onde apenas idosos ou aposentados podem se filiar), as alas femininas da torcidas organizadas e as torcidas voltadas para o público homossexual, antes de ser torcida organizada, é uma forma de se proteger na esfera futebolística, onde qualquer forma de estigmatização é válida em nome da rivalidade. Neste sentido, a forma pacífica e, quase sempre, lúdica desse tipo de torcida reflete uma estrutura mais próxima do estilo de organização das antigas torcidas uniformizadas, do que das atuais - altamente burocratizadas e capitalizadas - torcidas organizadas.

\section{Bibliografia:}

AGOSTINO, Gilberto. Vencer ou Morrer: Futebol, Geopolítica e Identidade Nacional. Rio de Janeiro: FAPERJ: Mauad, 2002.

BRASIL, Lei Federal n.10.671, de 15 de maio de 2003.

BRASIL, Lei Federal n.12.299, de 27 de julho de 2010.

BRASIL, Lei Federal n.12.663, de 05 de junho de 2012.

BRASIL, Lei Federal n.13.155, de 04 de agosto de 2015.

DA MATTA, Roberto. Universo do Futebol: esporte e sociedade brasileira. Rio de Janeiro: Pinakotheke, 1982.

ELIAS, Norbert. Parte II: sinopse - Sugestões para uma Teoria de Processos Civilizadores - In: O

Processo Civilizador. Volume 2: A formação do Estado e Civilização. Tradução Ruy Jungman; revisão e apresentação Renato Janine Ribeiro - Rio de Janeiro: Jorge Zahar Ed., 1993, vol. 2, p. 193-297 
Mudanças na Agressividade. In: O Processo Civilizador. Volume 1: Uma história dos costumes. Tradução Ruy Jungman; Revisão e apresentação Renato Janine Ribeiro - Rio de Janeiro: Jorge Zahar Ed., 1994, 2.v. p. 189-202.

. A sociedade dos Indivíduos. Org.: Michael Schröter. Tradução Vera Ribeiro; Revisão técnica e notas Renato Janine Ribeiro - Rio de Janeiro: Jorge Zahar Ed., 1994.

. Envolvimento e Alienação. Editor Alemão: Michael Schröter; traduzido do inglês por Álvaro de Sá - Rio de Janeiro: Bertrand Brasil, 1998.

Os estabelecidos e os outsiders: sociologia das relações de poder a partir de uma pequena comunidade. Tradução: Vera Ribeiro - Rio de Janeiro: Jorge Zahar Editor, 2000.

. A Sociedade de Corte: investigação sobre a sociologia da realeza e da aristocracia da corte. Tradução: Pedro Süssekind - Rio de Janeiro: Jorge Zahar Editor, 2001.

FOER, Franklin. Como o Futebol Explica o Mundo: Um Olhar Inesperado sobre a Globalização. Tradução Carlos Alberto Medeiros - Rio de Janeiro: Jorge Zahar Ed., 2005.

GILBERTO, André Marques. A aplicação do Estatuto do Torcedor não será tarefa simples. Revista Consultor Jurídico, São Paulo, 09 jun. 2003. Disponível em <http://www.conjur.com.br/2003-jun-09/passo_importante_moralizacao_esporte> Acesso em: 22 ago. 2009.

GOMES, Luiz Flávio. Novo Estatuto do Torcedor: mais populismo penal enganoso. Disponível em http://www.lfg.com.br - 03 de dezembro de 2013.

HELAL, Ronaldo. O que é Sociologia do Esporte. São Paulo: Editora Brasiliense S.A., 1990.

LEVER, Janet. A Loucura do Futebol / Tradução de A. B. Pinheiro de Lemos. Rio de Janeiro: Editora Record, 1983.

LOBO, Felipe. Leis existem, mas o Estado precisa agir para coibir a violência no futebol. Portal Trivela. 28 de out. de 2014. Disponível em: <http://trivela.uol.com.br/leis-existem-mas-oestado-precisa-agir-para-coibir-violencia-futebol/>. Acesso em 01 de novembro de 2015.

MENDONÇA, Renata. Violência no futebol: debate sobre soluções tem 'jogo de empurra' e desacordos. BBC Brasil. 12 de fev. 2015. Disponível em: <http://www.bbc.com/portuguese/noticias/2015/02/150211_futebol_briga_torcidas_rm>. Acesso em 01 de novembro de 2015.

MURPHY, Patrick et al. O futebol no Banco dos réus: violência dos espectadores num desporto em mudança. Tradução Raul de Sousa Machado; Revisão técnica João S. Batista Oeiras: Celta, 1994.

PIMENTA, Carlos Alberto Máximo. Torcidas Organizadas de Futebol - Violência e autoafirmação - aspectos da construção das novas relações Sociais. Taubaté: Vogal Editora, 1997.

- Violência entre Torcidas Organizadas de Futebol. São

Paulo Perspec. vol.14 no.2 São Paulo Apr./June 2000. Disponível em: <http://www.scielo.br/scielo.php?pid=S0102-88392000000200015\&script=sci_arttext $>$. Acesso em 10 de nov. de 2015.

SESMA, Edson. O Polêmico Estatuto e a Responsabilidade Objetiva. Consultor Jurídico, São Paulo, 11 jun. 2003. Disponível em <http://www.conjur.com.br/2003-jun11/estatuto_defesa torcedor_proposta_inovadora $>$ Acesso em: 16 jul. 2009.

TOLEDO, Luiz Henrique de. Torcidas Organizadas de Futebol. Campinas: Editora Autores e Associados / Anpocs, 1996.

No país do futebol. Rio de Janeiro: Jorge Zahar Editor, 2000. 